states of the hydrogen atom could be worked out by students-this would give confidence that more complete treatments for more complex systems would in fact yield the correct answer.

As an example of the dangers in all elementary accounts, Prof. Coulson cited the frequent misuse of the word 'resonance'. A critique of this concept should be regarded as part of any course on wave mechanics, and leads easily and naturally to a discussion of the true status of wave mechanics, as a most valuable conceptual tool, which gives insight into chemical phenomena, but which is severely limited if accurate $a b$ initio calculations are desired. No electronic computer will replace a chemical laboratory.

The third main paper was read by Mr. G. I. Brown (Eton), who gave as the duty of a science master that of understanding the developments in science and interpreting and presenting them in a simplified form to the uninitiated. He considered it important that there should be no undue delay in incorporating new advances into school teaching. This is no easy task for the teacher, and Mr. Brown urged more liaison between active teachers in universities and schools. $\mathrm{He}$ welcomed tho opportunity for this discussion, also, because it provided a chance of emphasizing the attractions of a teaching career. The teaching of chemistry can be made both interesting and attractive by the variety of possible ways of presenting it, and by the different requirements of students. He stressed that the advanced course of chemistry at school must never be a narrow one, but should give some indication of the importance of all the aspects of chemistry. Each teacher must to some extent decide on the type of approach to be adopted. However, the recent trend towards an undue emphasis on the social and economic aspect was deprecated as one which can too easily give the impression that chemistry is solely concerned with such things as nylon underwear.

Mr. Brown considered that the basis of the course for sixth-form science students should be a theoretical one, involving a study of fundamental chemical principles. Of these the most useful as a unifying framework is modern valency theory. Chemistry is often criticized as a school subject on the grounds that it can be learnt simply by perseverance and hard work, and that it involves too little real thinking. It is true that, below sixth-form level, chemistry cannot fail to be largely a matter of routine learning of apparently unconnected facts-but young boys make no objection to learning the facts, and many have little difficulty in doing so. What is difficult, at this stage, is to exercise the mind of the student in the same way as it is exercised in the learning of, say, mathematics or Latin. There comes a time, usually while still at school, when a boy begins to ask more fundamental questions-and then his mind must be stimulated by something more than a mere catalogue. Mr. Brown expressed his belief that modern valency theory provides the necessary interest, and that despite the criticisms levelled against its introduction in school-teaching, the benefits derived from its use far outweigh the reduction in factual knowledge implied by a change in the balance of study.

Mr. Brown was critical of examining bodies who continue to set questions requiring for their answer the recollection of far too many unimportant facts, and pointed out that the quickest and most effective way of changing the character of school-teaching is to change examination syllabuses and the nature of the examination questions.

The two main contributors to the general discussion which followed were Mr. J. C. Stredder (Tonbridge) and Mr. A. C. Cavell (Uppingham). Mr. Stredder, while not rejecting the incorporation of more recent theories in teaching at school, stressed the dangers of such a policy. He was particularly concerned that an inexperienced pupil, who is unable to criticize-and perhaps unable to understand-the experimental evidence on which modern theories are based, must either allow his critical faculty to be dulled, or must accept such theories as fairy-tales in which he may one day believe. There is a danger that not only facts but also theories will be learned parrot-fashion. Furthermore, the introduction of many modern ideas must depend on the pupil having a sufficient background in physics; and often this cannot be provided adequately at school. Mr. Stredder was of the opinion that, with some exceptions, boys are scarcely ready to be introduced to subjects such as the wave nature of the electron, atomic orbitals, resonance and molecular orbitals until they enter a university.

Mr. Cavell was anxious that developments in chemistry teaching in schools should take account of the educational as well as the more specialized technical aspects. He expressed the view that both schools and universities are attempting to teach too wide a syllabus in science, and that by introducing too much detail, insufficient time is available for dealing with basic principles. While agreeing with Mr. Brown that modern valency theory helps to make sense of chemistry, and encourages thought and discussion, Mr. Cavell said that in his experience the evidence provided by school certificate scripts suggests that either this approach is not being widely used, or that candidates are averse to using it in answering examination questions. His agreement with Prof. Everett, that a rational rather than a strictly historical approach is to be preferred, was qualified by the view that one of the fundamental educational weaknesses of science is that it deals more with things than with people. Consequently, he argued, no opportunity should be lost of introducing historical and biographical detail in an attempt to humanize the subject. Mr. Cavell also appoaled for eloser co-operation between teachers in school and university, especially in connexion with the revision of school syllabuses, the provision of courses for science teachers at universities, and on detailed techniques of science teaching.

\section{PROPERTIES AND DISTRIBUTION PROBLEMS OF RAW COTTON}
A
ONE-DAY conference on "Raw Cotton, its Properties and Distribution", arranged by the Manchester and District Section of the Textile Institute, was held in Liverpool on November 23 to facilitate the participation of raw-cotton merchants in discussing current problems in the growing and maxketing of raw cotton with the spinning and weaving sides of the cotton industry. It was also hoped that the conference would illustrate part of the wide field of activities undertaken by the Textile Institute and so encourage the formation of a Liver- pool section. Four papers were presented for con- 
sideration and discussion : genetics, by Prof. S. C. Harland (professor of botany in the University of Manchester) ; cotton quality and its assessment, by E. Lord (British Cotton Industry Research Association) ; spinners' requirements, by A. Draper (William Birtwistle Allied Mills, Ltd., Preston) ; and supply and marketing, by W. B. Hutchinson (Major Cleaver and Co., Liverpool).

Partly through necessity, the cotton industry is accustomed to handling variable material, and both marketing and industrial processing are organized to minimize the effects of quality variations. Prof. Harland outlined how large differences between the main groups of commercial cottons are mainly genetical in character, but environmental factors also produce appreciable effects. Variability in the many characters of the fibres in a given cotton sample starts with marked regional variation over the surface of the seed and is progressively increased by additional variation associated with seed to seed, boll to boll and plant to plant differences. Samples of the same strain, but different origin, often show pronounced locality and seasonal effects. Yield is of paramount importance to the grower and so far has received the most attention in the breeding programmes of various research stations. Nevertheless, cotton quality can be improved appreciably by the applications of genetical methods, both by reducing the variability and increasing the average fibre quality. Some past achievements along these lines in various countries were reviewed, and Prof. Harland also pointed out that as yet we are not able to formulate or even envisage the future upper limit that it may be possible to reach by cotton breeding. A valuable development during recent years is the increasing use of spinning tests to measure directly particular yarn features in preference to the previous almost complete dependence on a range of individual fibre tests.

For many years, and still to a large extent, the various features of raw cotton have been appraised commercially by subjective methods, particularly by making assessments based on the visual appreciation of appearance and on tactile impressions noted during manual manipulation of the fibres. A high degree of skill in the classification of cotton quality may come with long experience; but it remains largely a personal matter. Mr. Lord reviewed many of the 'Iaboratory' methods which have been developed to furnish separate objective evaluations of the various characteristics affecting cotton quality and commented on their accuracy, ease of use, limitations and scope of application. Determination of fibre length may be effected in several ways. In some methods, complete estimation of the several aspects of the distribution of fibre length may be made by tests largely dependent on the skill of the operator. In others, special fibre arrangements may be prepared and measured by the use of photoelectric scanning devices. The cotton fibre is a hollow, flattened and twisted single cell which grows out of the epidermis of the seed. Both perimeter and the degree of wall thickening are of industrial importance; but direct rapid measurement of these features is not generally feasible because of difficulties of technique and the high inter-fibre variation. Tests based on the determination of the weight per unit length and on the microscopical classification of swollen fibres have been developed to furnish indirect estimates of fineness and thickening. These methods have found widespread application, although they are slow in the light of classers' requirements. Measurement of the air permeability of compressed plugs of cotton fibres affords a rapid and reasonably accurate method of assessing specific fibre surface. The specific surface is determined both by the fibre fineness and the cell-wall thickening, and hence the practical interpretation of flow estimates demands care. Fibre strength is of prime technical importance and is most easily measured on bundles of parallel fibres. The structure and growth of cotton are such that weak places occur at irregular intervals along each fibre, and this leads to a marked dependence of measured fibre strength on the length of test specimen, so that no single set of experimental conditions affords a means of fully assessing the separate strength characteristics. Cotton 'grade' was another feature briefly reviewed at the conference. The 'Shirley' analyser is a mechanical tester for the determination of the trash or foreign content of cotton, one quantity largely influencing the classified grade. The assessment of particular reflectance characteristics of cotton may be made on the automatic Nickerson-Hunter cotton colorimeter. Observations on this instrument correlate well with the visual grade classifications of American cotton. Commercial applications of the colorimeter are limited by the price, but its use in maintaining a regular check on the choice and formation of physical standards of grade is now established in the United States and should prove valuable in avoiding small but pro. gressive changes which have occurred in the past.

Mr. Draper commented further on the application of fibre and spinning test methods to the choice and olassification of raw cotton. Most objective tests are still too lengthy to permit their being applied to all commercial samples. Nevertheless, there is a strong need for representative scientific data to be available to the grower, merchant and spinner in order to encourage the production of more suitable material and to detect quickly those growths in which deterioration is occurring. He felt that in some instances the side of the industry concerned with growing might have exploited scientific tests to indicate how closely quality can be cut without incurring undue complaint instead of exploring more fully the possibilities of developing new strains of better general quality or with special. ized characteristics for competing or blending with man-made fibres. Mr. Draper also outlined in detail some of the ways in which practices of merchanting raw cotton in Great Britain might usefully be extended in order to meet more satisfactorily the requirements of the spinner.

Mr. Hutchinson surveyed the basic principles of the organization of cotton marketing. The present pattern in Britain has been gradually developed to fill many varied needs. It must provide a selling link between the small grower and the consumer and maintain classification methods to ensure reasonable continuity in quality despite regional and seasonal fluctuations. Marketing organization on a wide scale requires a complex price-structure to cope with rapidly changing supply and demand, with intermittent government interference through monetary controls and crop limitations, and with the problems arising through price changes during the often lengthy period which elapses between harvesting the crop and the final production of textile articles. The use of scientific tests to determine cotton quality is a development of significance which cannot be ignored. Merchants must examine these methods 
and place them in proper perspective in the general framework of trading. Stress was laid by $\mathrm{Mr}$. Hutchinson on the need for merchants and also spinners to have the fullest information available about the various characteristics of both main growths and new varieties. He said that at first it would probably be found better to superimpose any new tests on the established systems of classifications than to set up new systems. Nevertheless, marked additional sub-classification would certainly give rise to serious marketing difficulties. Selling would be made more complicated because many test results cannot be used as a basis for trading values, choice of material might be more restricted, and prices would be increased by higher classification costs, while adequate cover against price changes could not be arranged to cope with a multiplicity of qualities. There might be more scope for the use of scientific tests in normal 'spot' trading of cotton for immediate consumption than in 'futures' trading for covering price changes.

\section{SYMPOSIUM ON THIOCTIC ACID}

A

SYMPOSIUM on the chemistry, biochemistry and pharmacology of thioctic acid was held during November 28 and 29 at the Institute of Pharmacology of the University of Naples. There were about a hundred participants, including Profs. Bovet, Chain, Condorelli and Rossi-Fanelli (Rome), Prof. Theorell (Stockholm) and Prof. Vannotti (Lausanne), apart from the speakers.

The symposium was introduced by Prof. D. Marotta, director of the Istituto Superiore di Sanità (Rome), and the first lecture was given by Prof. M. Calvin (California), who discussed the part played by thioctic acid in the photosynthetic cycle. Prof. Calvin reported the isolation, with the help of ${ }^{35} \mathrm{~S}$-labelled thioctic acid, of the natural active form from the plastids of algae. It is probable that, in this form, the carboxyl group of thioctic acid is bound in an ester linkage to a hydroxyl group of glycerol.

Prof. E. A. Braude (London) followed with an account of the synthesis of thioctic acid. He described a new method which affords a good overall yield in few steps and represents the first application of the Prins reaction (addition of formaldehyde to an olefin) to the synthesis of a natural product.

The pharmacology of thioctic acid was discussed in a lecture by Prof. L. Donatelli, who stated that the lethal dose in rabbits, mice and other animals lies between 100 and $220 \mathrm{ml}$. per kgm. weight. A strong antitoxic action of thioctic acid was demonstrated for acute and chronic poisoning by mercuric chloride, arsenite, arsenobenzoles, carbon tetrachloride, aniline and isonicotinic acid hydrazide. A remarkable diuretic and choleretic effect was also observed in the rabbit.

The second day was devoted to the physiopathology and therapeutic applications of thioctic acid. Prof. P. Larizza (Cagliari) reviewed present knowledge on the part played by thioctic acid in biochemical processes and illustrated his experiments on phosphorus poisoning and steathogenic (Handler) diets in which thioctic acid normalizes the fat content of the liver. Prof. F. Rausch (Bad Rothenfelde) reported on the applications in human pathology, particularly in the awakening action on liver coma patients. This effect was confirmed by Yrof. A. Colarusso (Naples), who also discussed the liver-protecting action in hepatic cirrhosis and various forms of hepatitis. He noticed a remarkable diuretic effect on some of his patients with liver cirrhosis and congestive heart failure. The dose used was of the order of 20-50 mgm. per day, usually injected intravenously.

From these lectures and from the lively discussion which followed, it was clear that thioctic acid, apart from playing an important part in plant metabolism, may be a useful therapeutic agent, especially in diseases of the liver.

A. Segre

\section{WATER RESOURCES OF GREAT BRITAIN}

AONG with the news of the reconstitution of the A Central Advisory Water Committee (Nature, October 22) comes the welcome reappearance of "The Surface Water Year Book of Great Britain"*. A complete survey of inland water resources involves details of rainfall, surface water and ground water. The "Year Book" provides information about the surface water resources of most drainage areas and their rainfalls, and rather more detailed information relating to rainfall alone is issued annually in "British Rainfall", published by the Meteorological Office. Details of ground water resources are not yet available, but active steps are being taken to acquire and issue this information.

The first three "Surface Water" volumes dealt with the periods $1935-36,1936-37$ and $1937-45$, and the fourth and present volume with the eight water years 1945-53. In the first two volumes the measurements reported were collected from various public and private organizations, and the distribution of the records was very uneven. This was improved in the third volume, and a further notable increased coverage occurs in the fourth volume largely as a result of the River Boards Act of 1948 .

In the present volume Great Britain is divided into 103 areas, each area corresponding to one or more river basins. Within each area there is, first, a general description of the region, the gauging stations and the records available. Monthly evaluations of the average general rainfall over the drainage area for the standard period 1881-1915 are given, and then follow tables of monthly discharges and run-off, together with monthly evaluations of the general rainfall. An indication of extreme discharges is also given.

Thus the presentation of the data, so far as the monthly flow records are concerned, closely follows the pattern of the third volume, but the new volume does not give daily discharges for each station or the tables of frequencies. The possible inclusion of these data and other relevant information is, however, under consideration for the next issue, which it is hoped will cover only one water year. Meanwhile, the issue of the fourth volume is a notable step towards the systematic collection and dissemination of the basic data necessary for the formulation of a much-needed national water policy in Great Britain. W. G. V. BaLCHIN * Ministry of Housing and Local Government : Scottish Office.
The Surface Water Year Book of Great Britain, 1945-53. (Hydrometric Statistics for British Rivers, together with related Rainfalls,
for the Eight Years ended 30th September, 1953.) Pp. xi+167. (London: H.M.S.O., 1955.) 358. net. 